\title{
Fouling Weight Quantification in Antibacterial Polymeric Membrane During Protein Washwater Ultrafiltration- Synergetic Effects of Silver Nanoparticles and Chitosan
}

\author{
Nur Mahirah Ismail ${ }^{1}$, Nora'aini Ali ${ }^{1,2, *(\mathbb{D})}$, Diyana Kamarudin ${ }^{3(\mathbb{D})}$, Norhafiza Ilyana Yatim ${ }^{2(\mathbb{D})}$ \\ 1 Faculty of Ocean Engineering Technology and Informatics, Universiti Malaysia Terengganu, 21030 Kuala Nerus, \\ Terengganu, Malaysia \\ 2 Institute of Tropical Aquaculture and Fisheries, Universiti Malaysia Terengganu, 21030 Kuala Nerus, Terengganu, \\ Malaysia \\ 3 Department of Chemical Engineering, Faculty of Engineering, University of Malaya, 50603 Kuala Lumpur, Malaysia \\ * Correspondence: noraaini@umt.edu.my;
}

Scopus Author ID 15838741500

Received: 1.10.2020; Revised: 22.10.2020; Accepted: 23.10.2020; Published: 25.10.2020

\begin{abstract}
Controlling biofouling caused by bacterial growth onto the membrane surface and pores is essential when dealing with protein-based solutes to reduce cost and environmental impacts. Thus, this study was carried out to determine the effect of silver nanoparticles on fouling occurrence during surimi wash water ultrafiltration. Silver nanoparticles and chitosan were chosen as a bacteria inhibitor due to its remarkable antibacterial properties. The fouling weight represented the number of foulants attached to the membrane. These experiments were conducted by using the native PES membrane in comparison with the PES-Ag membrane, PES-Chitosan membrane, and PES-Ag-Chitosan membrane at a controlled condition where surimi wash water applied as a model protein. Foulant weight was significantly reduced by $56 \%$ for the PES-Ag-Chitosan membrane as compared to other membranes. It also indicates that silver nanoparticles and chitosan have the synergistic effect in overcoming the fouling contributed by both solutes depositions and bacterial growth as the total fouling weight of PES-Ag-chitosan is reduced almost 53\% and 50\% as compared to employing only chitosan and only silver nanoparticles, respectively.
\end{abstract}

Keywords: membrane biofouling; foulant weight quantification; silver nanoparticles membrane.

(C) 2020 by the authors. This article is an open-access article distributed under the terms and conditions of the Creative Commons Attribution (CC BY) license (https://creativecommons.org/licenses/by/4.0/).

\section{Introduction}

Membrane technology has evolved dramatically over the last two decades. It has also expanded its use for various purposes, such as in the health and medical, petrochemical, and environmental cleaning industries. Depending on their properties, various types of membranes are commonly used for different types of applications. Membrane separation mechanism is purely physical, where the separation is driven by potential mechanical gradient, electrical potential gradient, potential chemical gradient, or heat.

The application of membrane technology is easily affected by fouling phenomena despite its reliability and ease of handling, which have led to a great deal of emphasis on membrane separation technology today [1]. One of the main phenomena of fouling is biofouling, where it remains one of the significant problems that impede the widespread use of membrane technology [2]. To date, there is still little comprehensive research on the contribution of biofouling to the membrane [3]. Membrane biofouling is mainly a result of 
microbial growth where it significantly limits the separation performance and production capability by clogging the membranes; hence the permeability will be reduced. Bacteria in water samples form recalcitrant biofilms, which are irreversibly attached to the membrane surface [4]. This situation will lead to a significant increment in the cost of membrane separation processes due to higher energy consumption and shorter membrane life spans [5].

Membrane surface chemistry plays an important role in enhancing the separation performance. A large number of attempts have been made to improve the biofouling behavior of available membranes by increasing the hydrophilic character of the membrane surface since bacteria are more likely to attach to hydrophobic membrane surfaces to initiate membrane biofouling [6]. Recently, the impregnation of metal nanoparticles into the polymeric membrane has been the primary focus and provides a newly emerging approach to inducing hydrophilic surface and antimicrobial surface films.

Among all the metal nanoparticles that are impregnated in polymeric membrane film, the use of silver nanoparticles has drawn considerable attention for its effectiveness at reducing membrane biofouling [7]. It exhibits a remarkable antibacterial activity and has a longer-lasting bacterial effect [8]. Biofouling may be solved by the combination of antibacterial properties of silver nanoparticles and membrane chemistry [9] due to the excellent antibacterial performance of silver nanoparticles as compared to other metal nanoparticles [10].

Even when silver nanoparticles are applied, fouling will occur and cannot be eliminated. On the other hand, chitosan is natural flocculants known for its biodegradable, nontoxic, biocompatible, and antibacterial properties [11]. The abundant source of chitosan as a biopolymer, making it the most favorable option as an antibacterial agent with its remarkable non-toxic effect $[12,13]$ applied in various applications, including water treatment [14-16].

Previously, fouling studies were carried out solely based on flux decline analysis. This research has been conducted to identify how far silver nanoparticles and chitosan can play their role in reducing biofouling by analyzing the fouling itself. Silver nanoparticles and chitosan have been proven to have a remarkable position in reducing biofouling. Still, this work was done to analyze fouling occurrence quantitatively so that the anti-biofouling properties of the PES-Ag-Chi membrane could be justified. By doing so, a proper and suitable clean-in-place procedure could be proposed and employed in order to best apply the biofouling mitigation strategy in ultrafiltration membrane applications.

\section{Materials and Methods}

\subsection{Membranes preparation.}

All membranes were fabricated according to the dry-wet phase inversion technique with the composition of PES:NMP: $\mathrm{H}_{2} \mathrm{O}$ is equal to 15:77:8 wt $\%$. For the PES-Ag membrane, 1 wt $\%$ of $\mathrm{AgNO}_{3}$ was added into the dope solution. During this process, $\mathrm{AgNO}_{3}$ had undergone a reduction process where it was converted into Ag nanoparticles. $0.5 \mathrm{wt} \%$ of polyvinylidene pyrrolidone (molecular weight: $10000 \mathrm{Da}$ ) was added into the dope solution of PES-Ag as a capping agent to ensure the encapsulation of $\mathrm{Ag}$ nanoparticles inside the membrane pores. Then, the membranes were cast on a glass plate with a knife gap of $20 \mu \mathrm{m}$.

\subsection{Preparation of surimi wash water.}

Surimi wash water was prepared from mince of freshwater fish, which was Pangasius $s p$. Firstly, the fish was headed and gutted before going through the deboning process where 
the fish flesh was separated from its bone and skin. The fish mince was washed with sufficient cold water at a ratio of 3 (cold water): 1 (fish mince). The mixture of fish mince with water was then centrifuged at $3000 \mathrm{~g}$ ( $\mathrm{g}$ is Relative Centrifugal Force) for 6 minutes at $4^{\circ} \mathrm{C}$. The supernatant was collected and preserved as a sample of surimi wash water. Sodium hydroxide $(\mathrm{NaOH}) 5.0 \mathrm{M}$ and hydrochloric acid $(\mathrm{HCl}) 5.0 \mathrm{M}$ were used to treat the sample to maintain its $\mathrm{pH}$ at 6.

\subsection{Determination of fouling weight.}

Ultrafiltration experiment was conducted on a dead-end stirred membrane cell with an effective filtration area of $14.6 \mathrm{~cm}^{2}$. The protein ultrafiltration process was performed by using surimi wash water as a feed solution at a pressure of 5 bar for different filtration durations, which were 30, 60, 90, and 120 minutes. The permeate flux was recorded. Virgin membranes, as well as fouled membranes, were desiccated at room temperature. The thermogravimetric analyzer was used to determine the fouling weight of the membranes. Fouling weight (FW) could be defined as the weight of foulants attached to the unit membrane surface area after a period of filtration [17], where it consists of volatile fouling weight (VFW) and non-volatile fouling weight (NVFW). By employing the thermogravimetric method, the weight loss of membranes and foulants were obtained as the materials were heated up to a high temperature so that the plots of weight loss versus temperature (temperature-scan curves) were obtained from the TGA. Volatile fouling weight and non-volatile fouling weight were calculated from the data collected from TGA by using equations 1 and 2, respectively.

$$
\begin{aligned}
& V F W=a_{m} \frac{W_{v}}{W_{m}} a_{m} \frac{\eta_{m}^{T 1}-\eta_{f}^{T 1}}{\eta_{f}^{T 1}-\eta_{v}^{T 1}} \\
& N V F W=a_{m} \frac{\eta_{f}^{T 2}-\eta_{m}^{T 2}}{1-\eta_{f}^{T 2}}
\end{aligned}
$$

Where; $a_{m}=$ surface density of membrane (weight per unit surface area of the membrane)

$\mathrm{W}_{\mathrm{v}}=$ weight of volatile fouling material

$\mathrm{W}_{\mathrm{m}}=$ weight of the fresh membrane

$\eta_{f}^{T 1}=$ percentage of the weight of the remaining portion of the fouled membrane at $\mathrm{T}_{1}$

$\eta_{m}^{T 1}=$ percentage of the weight of the remaining portion of the fresh membrane at $\mathrm{T}_{1}$

$\eta_{v}^{T 1}=$ percentage of the weight of the remaining portion of volatile fouling material at $\mathrm{T}_{1}$

$\eta_{f}^{T 2}=$ percentage of the weight of the remaining portion of the fouled membrane at $\mathrm{T}_{2}$ $\eta_{m}^{T 2}=$ percentage of the weight of the remaining portion of the fresh membrane at $\mathrm{T}_{2}$

\section{Results and Discussion}

\subsection{Characteristics of membranes.}

The permeability coefficient, $\mathrm{Pm}$ is a crucial indicator to illustrate the degree of membrane porosity, intrinsic hydrodynamic resistance, and flux throughput. It can be estimated as described in the Hagen-Poiseuille equation. The values of $\mathrm{P}_{\mathrm{m}}$ is derived by the statistical linear regression of volume flux, $\mathrm{J}_{\mathrm{v}}$ versus applied pressure, $\mathrm{Jv}=\mathrm{P}_{\mathrm{m}} \Delta \mathrm{P}$. Pure water flux plots for all fabricated membranes demonstrate a good correlation to the Hagen-Poiseuille equation, which indicates that the water flux increases proportionally with increasing applied pressure. 
All membranes exhibited the lowest flux at a pressure of 1 bar, and the flux increased linearly as the pressure increased up to 5 bar, as shown in Figure 1.

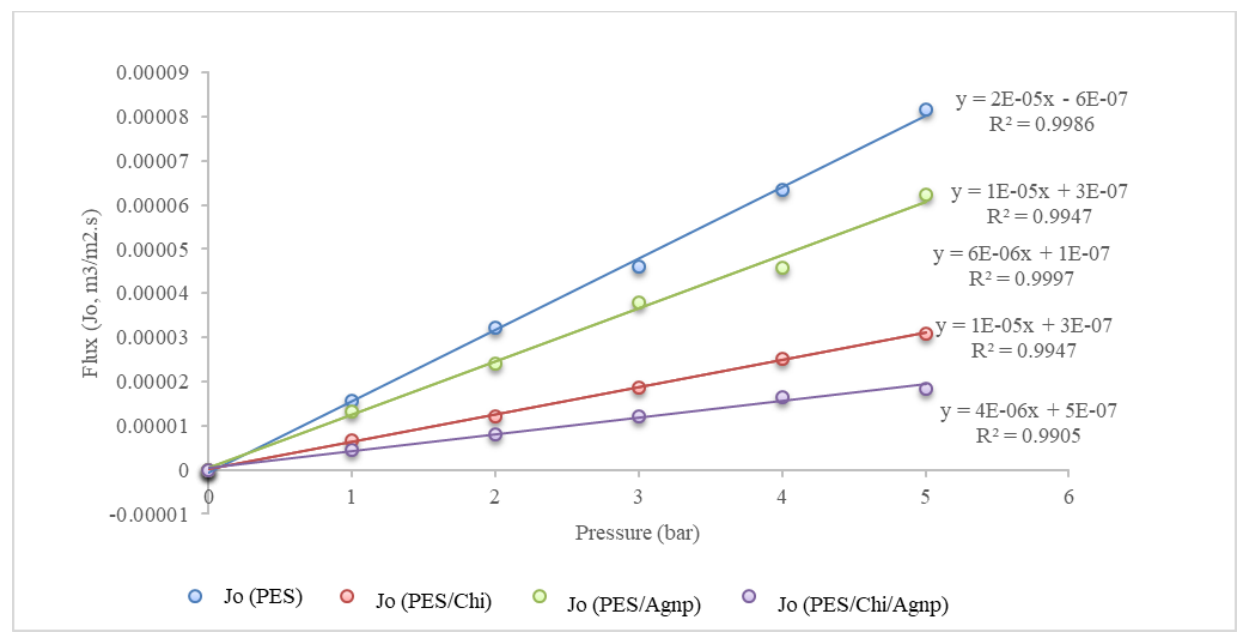

Figure 1. Pure water flux vs. pressure.

Table 1 tabulates the permeability of fabricated membranes in the range of ultrafiltration were the values of $P_{m}$ were $57.55 \mathrm{Lm}^{-2} \mathrm{~h}^{-1}$ and $43.76 \mathrm{Lm}^{-2} \mathrm{~h}^{-1}$ for PES membrane and PES-Ag membrane, respectively.

Table 1. Characteristics of fabricated membranes.

\begin{tabular}{l|c|c|c|c|c|c} 
Membrane ID & $\begin{array}{c}\text { Permeability } \\
\text { coefficient } \\
\mathbf{L} \mathbf{~ m}^{-\mathbf{2}} \mathbf{h}^{\mathbf{- 1}}\end{array}$ & $\begin{array}{c}\text { Regression } \\
\left.\text { Coefficient } \mathbf{( R}^{\mathbf{2}}\right)\end{array}$ & $\begin{array}{c}\text { MWCO } \\
\mathbf{( k D a )}\end{array}$ & $\begin{array}{c}\text { Porosity } \\
\mathbf{( \% )}\end{array}$ & $\begin{array}{c}\text { Contact } \\
\left.\text { angle } \mathbf{(}^{\circ}\right)\end{array}$ & $\begin{array}{c}\text { Protein } \\
\text { rejection } \\
(\mathbf{\%})\end{array}$ \\
\hline PES-native & 57.55 & 0.998 & 51.0 & 92 & 62 & 54.65 \\
\hline PES-Ag & 43.76 & 0.994 & 45.2 & 94 & 53 & 57.88 \\
\hline PES-Chitosan & 22.34 & 0.999 & 25.5 & 95.6 & 31.5 & 38.98 \\
\hline PES-Ag-Chitosan & 14.02 & 0.990 & 20.6 & 98.6 & 29.23 & 37.1
\end{tabular}

The molecular weight cut (MWCO) is widely used to measure the pore size and pore size distribution of the ultrafiltration membrane. Its value can be calculated from solute rejection experiments using known molecules with different ranges of molecular weights, which could be expressed by UF MWCO. Table 1 showed that the addition of silver nanoparticles to the PES dope solution had a minor impact on porosity and pore formation. The contact angle of the PES native membrane was $62^{\circ}$. With the addition of silver nanoparticles to the PES membrane, the contact angle was reduced by nearly $19 \%$. The lower contact angle was shown to have higher hydrophilicity of the PES-Ag membrane relative to the PES membrane, which postulates a decrease in biofouling.

A relatively similar porosity value for the PES membrane was approximately $92 \%$ and $94 \%$ for the PES-Ag membrane. The addition of chitosan-influenced membrane water flow, which is similar to the recent finding [18], where chitosan significantly improves the permeability of the PES membrane. The hydrophilicity of the PES membrane increased, related to the increase in water flux and a decrease in the fouling tendency. It also clarified the decrease in the contact angle due to an increase in membrane porosity [19]. It is worth noting that the inherent properties of the membrane that affect membrane fouling include the material, hydrophilicity/hydrophobicity, surface charge, roughness, pore size, porosity, and structure of the membrane module [20]. 


\subsection{Membrane morphology.}

From the cross-section images of the Scanning Electron Microscopy ( SEM), the occurrence, position, size, and uniformity of the pores can be seen. The expected typical asymmetrical structure, consisting of a well-developed skin layer and supported by a porous support layer with macro voids of the fabricated membranes, was shown. Figure 2 depicts the cross-sectional images of the PES-Ag membrane. It was found that the modified PES membrane with silver nanoparticles appeared the depositions of silver inside the pores of the membranes. This shows that the impregnation of silver nanoparticles into the PES membrane has occurred while the fabricated PES-Ag membrane has shown no significant difference in morphology as it had a similar structure characteristic with the native PES membrane, as shown in Figure 2(a).

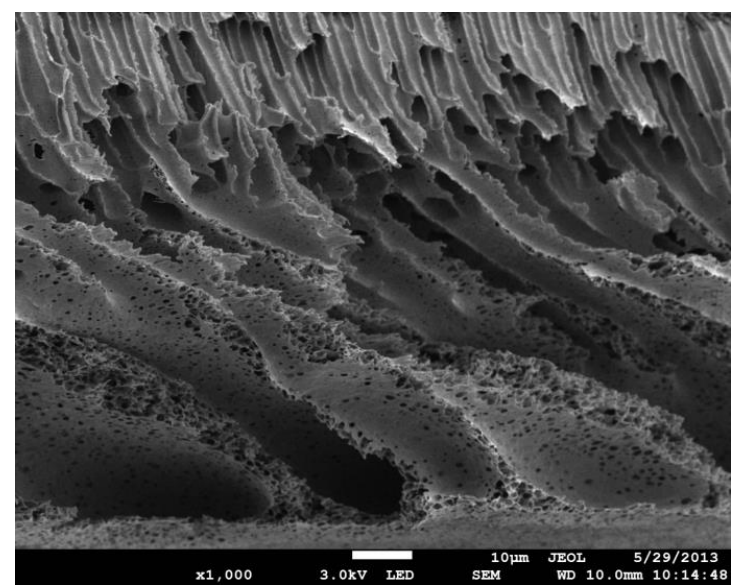

(a)

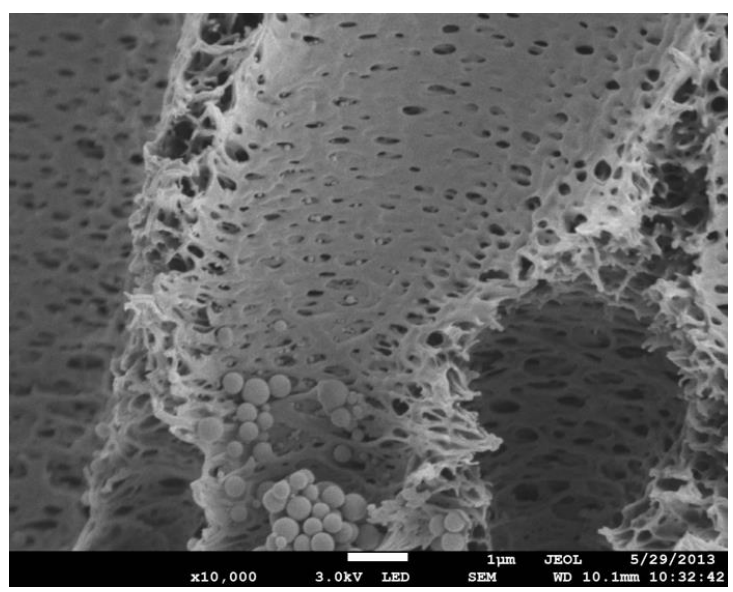

(b)

Figure 2. Cross-section of PES-Ag membrane at (a) 1000 times magnification (b) 10000 times magnification.

\subsection{Antibacterial activity.}

The antibacterial growth activity of silver nanoparticles was studied against grampositive and gram-negative bacteria, which were Staphylococcus aureus and Escherichia coli, respectively. After incubation at $37{ }^{\circ} \mathrm{C}$ for 24 hours, the PES-Ag and PES-Ag-Chi membranes showed positive results on the antibacterial effect, whereas the native PES membrane did not show the antibacterial effect on both types of bacteria. The antibacterial effect of PES-Ag and PES-Ag-Chi membranes has been illustrated by the formation of an inhibition ring for both types of bacteria, as shown in Figure 3. The PES-Ag-Chi membrane exhibits a more precise and wider inhibition ring against both types of bacteria due to its highest silver content compared to the PES-Ag membrane, where chitosan acted as a capping agent preventing the silver nanoparticles from being leached out. The diameter of the zone of inhibition of $S$. aureus and $E$. coli for PES-Ag-Chi membrane were $30 \pm 0.1$ and $25 \pm 0.1$, respectively, whereas the diameter of the zone of inhibition of $S$. aureus and E. coli for PES-Ag membrane were $25 \pm$ 0.1 and $18 \pm 0.1$ respectively. PES membrane (native) shown no antibacterial activity as confirmed by the bacterial growth around and below its surface. 


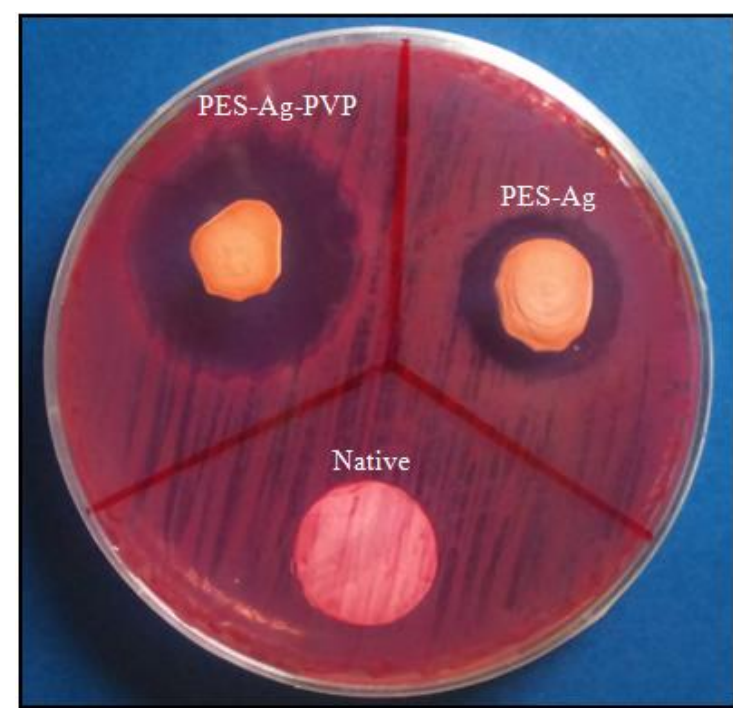

(a)

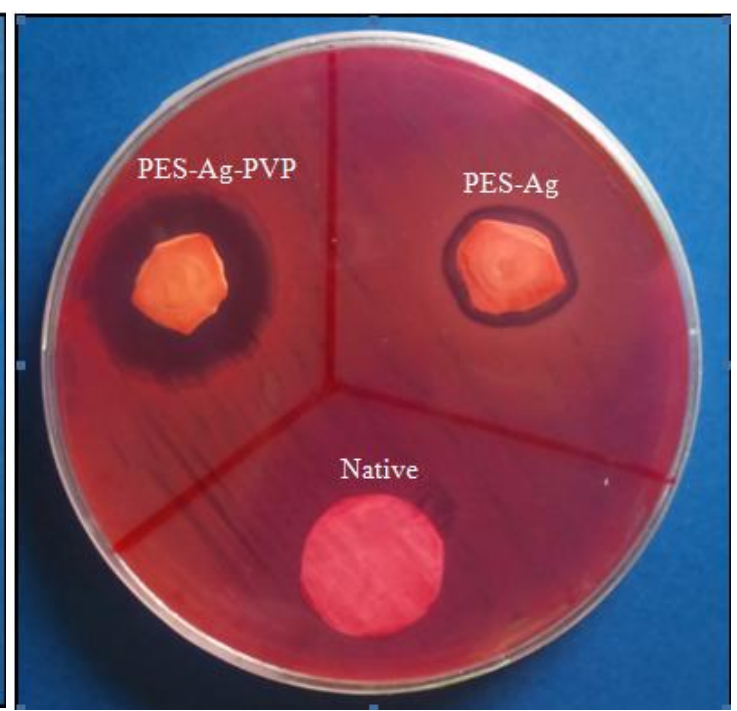

(b)

Figure 3. Inhibition rings of (a) S. aureus (b) E. coli.

\subsection{Overall spectrum of flux decline in surimi wash water ultrafiltration.}

The fabricated membranes (native and silver-modified have been filtered with surimi wash water for 120 minutes. The permeate flux for the ultrafiltration processes is depicted in Figure 4.

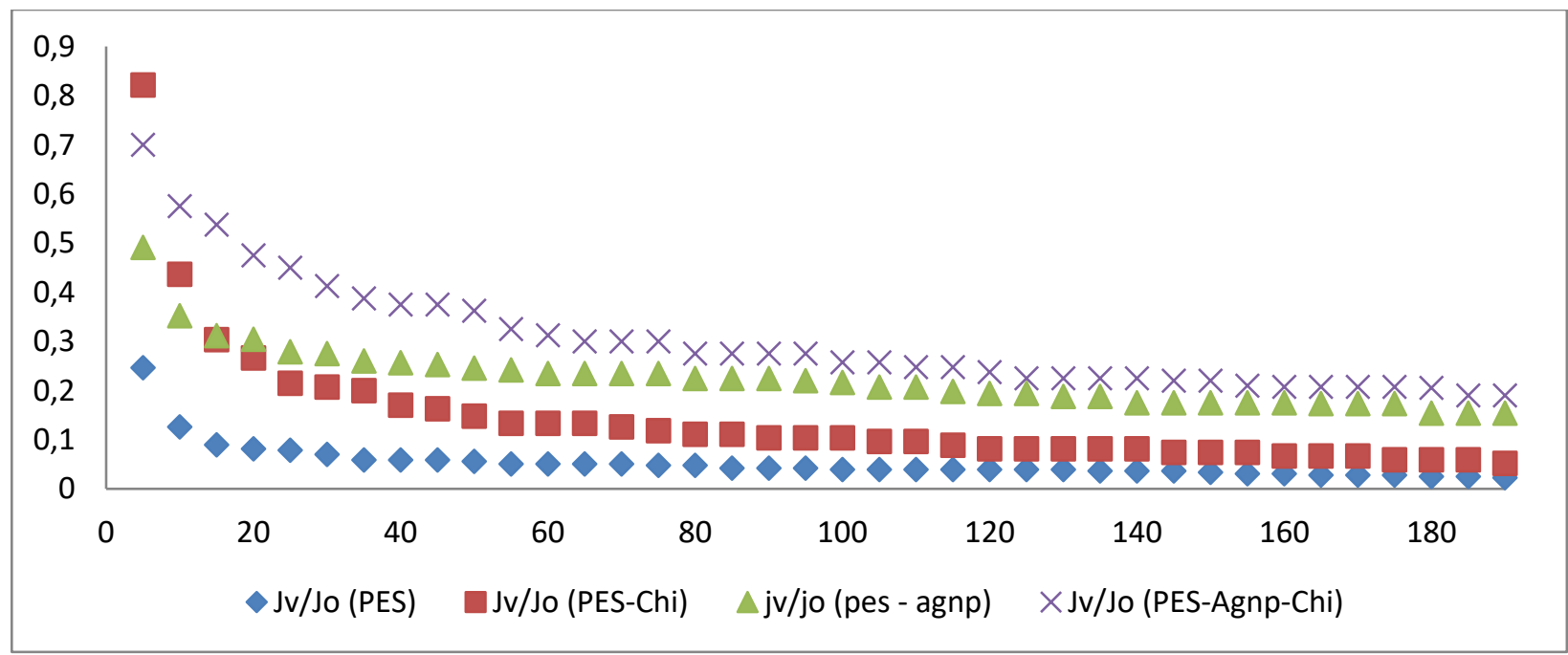

Figure 4. Flux versus time of surimi washes water ultrafiltration at 120 minutes.

From Figure 4, it was clearly shown that the native PES membranes have a lower permeate flux as compared to the PES-Ag membranes. It is because the accumulation of solutes and bacterial growth that leads to the fouling occurrence of the native membrane was greater than PES membranes incorporated with silver nanoparticles. The permeate flux has increased with the addition of silver nanoparticles into the membrane via the in-situ method, where the silver nanoparticles were deposited inside the membrane pores. The addition of PVP as an encapsulating agent also contributed towards this significant improvement of the permeate flux pattern since it held the silver nanoparticles closely onto the surface of membrane pores. Besides, the addition of silver nanoparticles shows a better permeation with the addition of silver nanoparticles shows that it has played an essential role in overcoming the fouling, in particular, the biofouling occurrence due to its antibacterial properties. Thus, it has been clearly 
shown that silver nanoparticles are a reliable solution for catering membrane fouling that has contributed to bacterial growth.

\subsection{Determination of fouling weight via thermogravimetric analysis.}

The fouling weight of all fouled membranes (PES, PES-Ag-Chi) was determined by using the thermogravimetric method. The temperature scan curves for the virgin and fouled PES-Ag-Chi membranes have been presented in Figure 5.

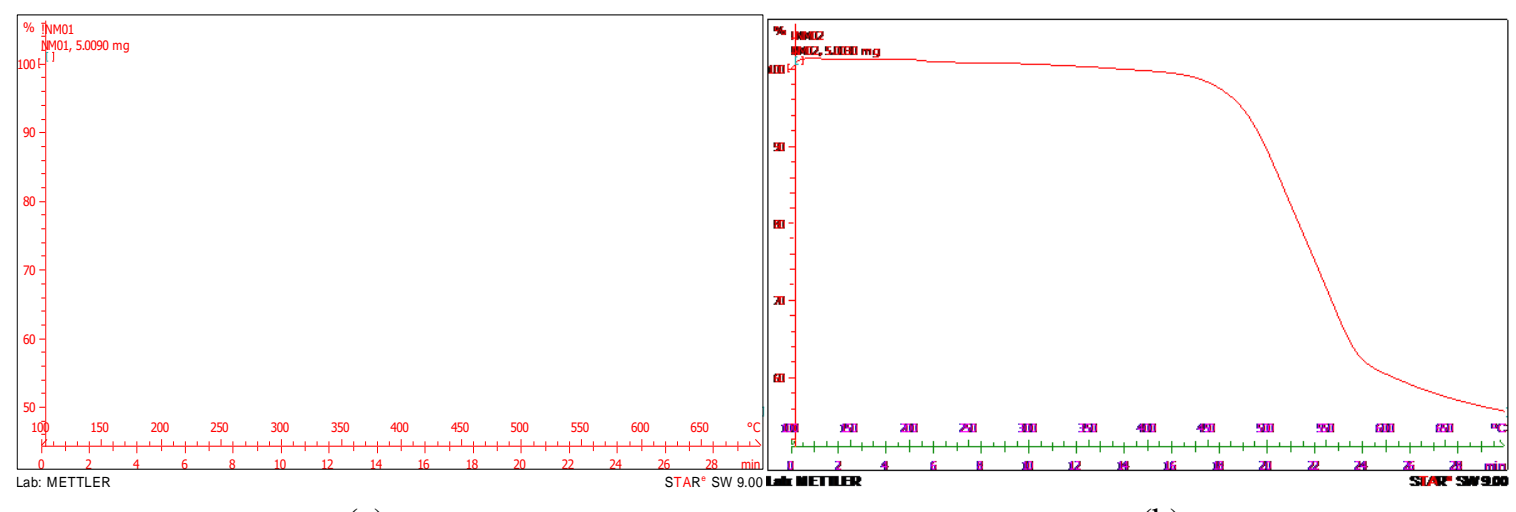

(a)

(b)

Figure 5. Temperature scan curves of (a) virgin PES-Ag-Chi and (b) fouled PES-Ag-Chi membranes.

Figure 5 shows the temperature-scan curve of the virgin and fouled PES-Ag-Chi membrane. As shown in Figure 5 (a), when a piece of fresh PES membrane was heated up, its weight did not change until the temperature reached $450^{\circ} \mathrm{C}$. Beyond this temperature, the membrane began to decompose and lost $40 \%$ by weight, which was the first fraction of membrane material. The second fraction of the PES-Ag membrane began to decompose at $580^{\circ} \mathrm{C}$, with the membrane losing $10 \%$ by weight when the temperature over $650^{\circ} \mathrm{C}$, the remaining part of the remaining membrane remained unchanged.

From the temperature-scan curve of the fouled membrane shown in Figure 5 (b), it can be seen that the curve shows both the foulant and the membrane. The fouled membrane began to decompose at $400{ }^{\circ} \mathrm{C}$. The decomposition at a temperature above $650{ }^{\circ} \mathrm{C}$ is attributed to the decomposition of inorganic matters and non-volatile fractions in the membrane.

Fouling weight could be categorized as two, i.e., volatile fouling weight (VFW) and non-volatile fouling weight $(\mathrm{NVFW})$. The volatile fouling weight was measured at lowtemperature range $\mathrm{T}_{1}\left(103{ }^{\circ} \mathrm{C}<\mathrm{T}_{1}<500{ }^{\circ} \mathrm{C}\right)$. The fouling weight of the volatile material was calculated using Eq.(1), whereas the non-volatile fouling weight was measured at hightemperature range $\mathrm{T}_{2}\left(\mathrm{~T}_{2}>500{ }^{\circ} \mathrm{C}\right)$. The fouling weight of a non-volatile material was calculated by using Eq.(2). The fouling weight values for both PES and PES-Ag-Chi membranes were tabulated in Table 2.

The total values of fouling weight were obtained by combining the values of volatile fouling weight with non-volatile fouling weight. The total fouling weight values of all fouled membranes for different filtration durations, as shown in Table 2. Table 2 showed that the fouling weight of the PES at 120 minutes of filtration duration was the highest with a value of $7.47 \times 10^{-5} \mathrm{Kg} / \mathrm{m}^{2}$. The fouling weight values were reduced by $10.8 \%-62.2 \%$ as the filtration durations were reduced. This phenomenon indicated an increase in the number of foulants accumulated on the membrane as the filtration progressed over a longer period. With the addition of silver nanoparticles into the PES membranes, the fouling weight was reduced by 
almost $14.9-62.2 \%$ for filtration duration of 30, 60, 90, and 120 minutes respectively. These values show that the fouling occurrence has been reduced by incorporating silver nanoparticles into PES membranes, where the total amount of fouling accumulated has been reduced, as shown by the decreasing values of the total fouling weight. The PES-Ag-Chi membrane has the lowest fouling weight values of $2.26 \times 10^{-5} \mathrm{Kg} / \mathrm{m}^{2}$ at 30 minutes of filtration duration, where the total amount of foulants accumulated was reduced by $20 \%$ as compared to the PESnative.

Table 2. Values of fouling weight for PES-native and PES-Ag membranes.

\begin{tabular}{l|l|l|l|l|l|l|l|l|l|l|l|l|}
\hline & Filtration duration (minutes) \\
\hline & 30 & 60 & 90 & 120 & 30 & 60 & 90 & 120 & 30 & 60 & 90 & 120 \\
\hline Membrane ID & VFW $\left(\mathrm{X} 10^{-5} \mathrm{~kg} / \mathrm{m}^{2}\right)$ & \multicolumn{1}{|c|}{ NVFW $\left(\mathrm{X} 10^{-5} \mathrm{~kg} / \mathrm{m}^{2}\right)$} & & \multicolumn{2}{l}{$\mathrm{FW}\left(\mathrm{X} 10^{-5} \mathrm{~kg} / \mathrm{m}^{2}\right)$} & \\
\hline PES-native & 1.04 & 1.78 & 2.06 & 2.23 & 1.78 & 2.44 & 4.59 & 5.24 & 2.82 & 4.23 & 6.66 & 7.47 \\
\hline PES-Ag & 0.90 & 1.13 & 1.96 & 1.79 & 1.35 & 2.26 & 3.37 & 4.19 & 2.26 & 3.38 & 5.33 & 5.98
\end{tabular}

In this study, the total fouling weight values of all membranes at each specific time interval were different and increased as the filtration durations were increased. This condition could be explained by the correlation of the total amount of fouling weight reflected in filtration durations. The correlation was depicted in Figure 6.

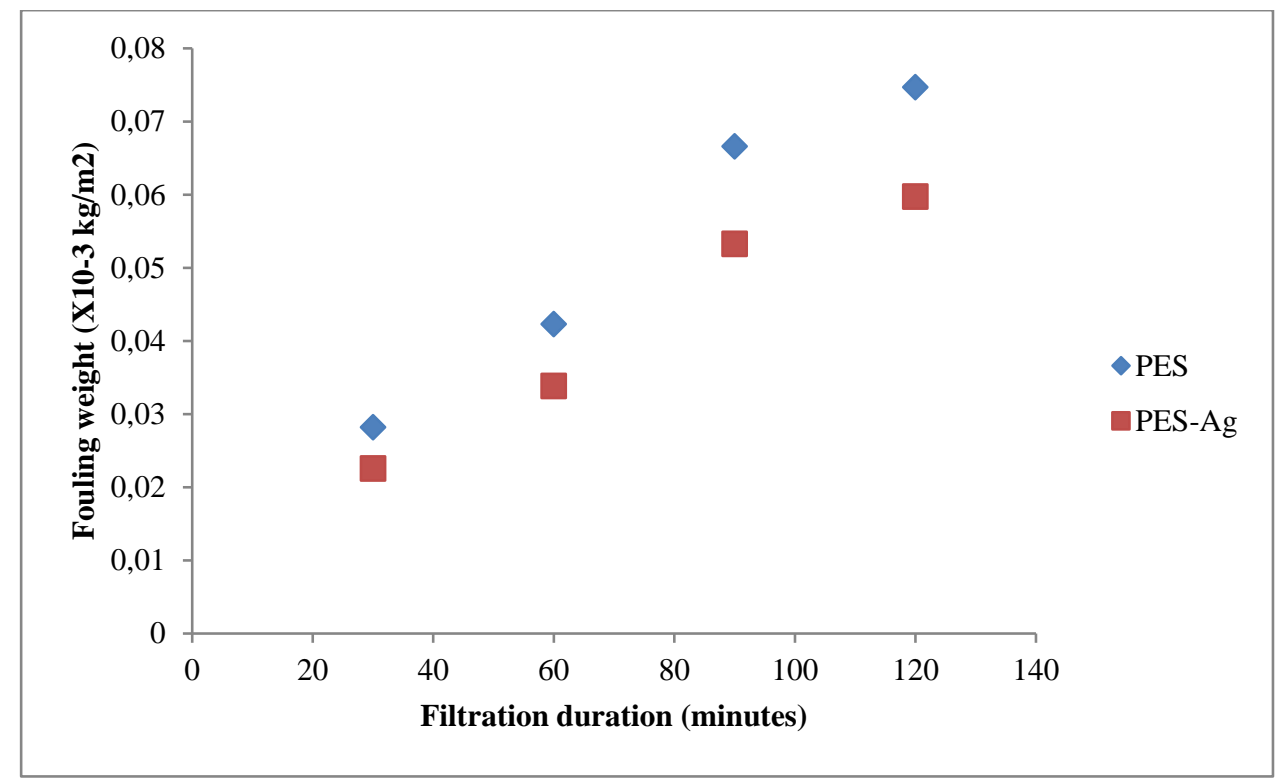

Figure 6. Total fouling weight versus filtration durations.

Figure 6 shows that the values of the total fouling weight were linearly correlated with the filtration duration as there was a significant increase in the fouling weight values as the duration increased from one-time interval to another. This pattern could be seen in both membranes, but interestingly, unlike in the PES membrane, the increase in fouling weight barely occurred as the ultrafiltration of the PES-Ag-Chi membrane lasted from 90 minutes to 120 minutes. This situation has shown that the prepared PES-Ag-Chi membrane had almost the same characteristics and performance as the PES membrane but is still capable of reducing the fouling represented by the fouling weight values obtained from this study.

\section{Conclusions}

PES-Ag-Chi membranes with slightly different PES membranes have been successfully fabricated in terms of characteristics and performance. It has been shown that PES-Ag-Chi can successfully reduce the biofouling occurrence of surimi wash water ultrafiltration. Chitosan is 
a vital substance to enhance membrane hydrophilicity. Silver nanoparticles also played an essential role in the use of antibacterial agents, which improved the flow. The combination of these elements in the PES-Ag-Chi membrane can reduce solutes deposition and prevent bacterial growth, thereby increasing the flow by decreasing the incidence of fouling. Further consideration will be given in future studies as to whether other nanomaterials can be used to improve the reduction of biofouling further.

\section{Funding}

The authors would like to thanks the Ministry of Higher Education of Malaysia for funding this research through FRGS VOT59273.

\section{Acknowledgments}

The author gratefully acknowledges the Center of Research and Field Service, University Malaysia Terengganu, Malaysia, for providing research facilities.

\section{Conflicts of Interest}

The authors declare no conflict of interest.

\section{References}

1. Gu, Q.; Ng, H.Y.; Zhao, D.; Wang, J. Metal-Organic Frameworks (MOFs)-boosted filtration membrane technology for water sustainability. APL Materials 2020, 8, https://doi.org/10.1063/5.0002905.

2. Siebdrath, N.; Farhat, N.; Ding, W.; Kruithof, J.; Vrouwenvelder, J.S. Impact of membrane biofouling in the sequential development of performance indicators: Feed channel pressure drop, permeability, and salt rejection. Journal of Membrane Science 2019, 585, 199-207, https://doi.org/10.1016/j.memsci.2019.05.043.

3. Yu, X.; Lin, T.; Xu, H.; Tao, H.; Chen, W. Ultrafiltration of up-flow biological activated carbon effluent: Extracellular polymer biofouling mechanism and mitigation using pre-ozonation with $\mathrm{H} 2 \mathrm{O} 2$ backwashing. Water Research 2020, 186, https://doi.org/10.1016/j.watres.2020.116391.

4. Nagaraj, V.; Skillman, L.; Li, D.; Ho, G. Review-Bacteria and their extracellular polymeric substances causing biofouling on seawater reverse osmosis desalination membranes. Journal of environmental management 2018, 223, 586-599, https://doi.org/10.1016/j.jenvman.2018.05.088.

5. Couto, C.F.; Lange, L.C.; Amaral, M.C.S. A critical review on membrane separation processes applied to remove pharmaceutically active compounds from water and wastewater. Journal of water process engineering 2018, 26, 156-175, https://doi.org/10.1016/j.jwpe.2018.10.010.

6. Choudhury, R.R.; Gohil, J.M.; Mohanty, S.; Nayak, S.K. Antifouling, fouling release and antimicrobial materials for surface modification of reverse osmosis and nanofiltration membranes. Journal of Materials Chemistry A 2018, 6, 313-333, https://doi.org/10.1039/C7TA08627J.

7. Zou, D.; Chen, X.; Drioli, E.; Ke, X.; Qiu, M.; Fan, Y. Facile co-sintering process to fabricate sustainable antifouling silver nanoparticles (AgNPs)-enhanced tight ceramic ultrafiltration membranes for protein separation. Journal of Membrane Science 2020, 593, https://doi.org/10.1016/j.memsci.2019.117402.

8. Xiang, Y.; Mao, C.; Liu, X.; Cui, Z.; Jing, D.; Yang, X.; Liang, Y.; Li, Z.; Zhu, S.; Zheng, Y.; Yeung, K.W.K. Rapid and Superior Bacteria Killing of Carbon Quantum Dots/ZnO Decorated Injectable Folic AcidConjugated PDA Hydrogel through Dual-Light Triggered ROS and Membrane Permeability. Small 2019, 15, https://doi.org/10.1002/smll.201900322.

9. $\quad$ Beisl, S.; Monteiro, S.; Santos, R.; Figueiredo, A.S.; Sánchez-Loredo, M.G.; Lemos, M.A.; Lemos, F.; Minhalma, M.; De Pinho, M.N. Synthesis and bactericide activity of nanofiltration composite membranesCellulose acetate/silver nanoparticles and cellulose acetate/silver ion exchanged zeolites. Water research 2019, 149, 225-231, https://doi.org/10.1016/j.watres.2018.10.096.

10. Xie, Y.; Liao, X.; Zhang, J.; Yang, F.; Fan, Z. Novel chitosan hydrogels reinforced by silver nanoparticles with ultrahigh mechanical and high antibacterial properties for accelerating wound healing. International journal of biological macromolecules 2018, 119, 402-412, https://doi.org/10.1016/j.ijbiomac.2018.07.060.

11. Zhang, W.; Wang, H.; Li, L.; Li, D.; Wang, Q.; Xu, Q.; Wang, D. Impact of molecular structure and charge property of chitosan based polymers on flocculation conditioning of advanced anaerobically digested sludge for dewaterability improvement. Science of the total environment 2019, 670, 98-109, https://doi.org/10.1016/j.scitotenv.2019.03.156. 
12. Pounraj, S.; Somu, P.; Paul, S. Chitosan and graphene oxide hybrid nanocomposite film doped with silver nanoparticles efficiently prevents biofouling. Applied Surface Science 2018, 452, 487-497, https://doi.org/10.1016/j.apsusc.2018.05.009

13. Palla-Rubio, B.; Araújo-Gomes, N.; Fernández-Gutiérrez, M.; Rojo, L.; Suay, J.; Gurruchaga, M.; Goñi, I. Synthesis and characterization of silica-chitosan hybrid materials as antibacterial coatings for titanium implants. Carbohydrate polymers 2019, 203, 331-341, https://doi.org/10.1016/j.carbpol.2018.09.064

14. Khoerunnisa, F.; Rahmah, W.; Ooi, B.S.; Dwihermiati, E.; Nashrah, N.; Fatimah, S.; Ko, Y.G.; Ng, E.P. Chitosan/PEG/MWCNT/Iodine composite membrane with enhanced antibacterial properties for dye wastewater treatment. Journal of Environmental Chemical Engineering 2020, 8, https://doi.org/10.1016/j.jece.2020.103686.

15. Menazea, A.A.; Ezzat, H.A.; Omara, W.; Basyouni, O.H.; Ibrahim, S.A.; Mohamed, A.A.; Tawfik, W.; Ibrahim, M.A. Chitosan/graphene oxide composite as an effective removal of $\mathrm{Ni}, \mathrm{Cu}, \mathrm{As}, \mathrm{Cd}$ and $\mathrm{Pb}$ from wastewater. Computational and Theoretical Chemistry 2020, 1189, https://doi.org/10.1016/j.comptc.2020.112980.

16. Kumar, P.; Gihar, S.; Kumar, B.; Kumar, D. Synthesis and characterization of crosslinked chitosan for effective dye removal antibacterial activity. International journal of biological macromolecules 2019, 139, 752-759, https://doi.org/10.1016/j.ijbiomac.2019.08.058.

17. Storms, M.; Kadhem, A.J.; Xiang, S.; Bernards, M.; Gentile, G.J.; Fidalgo de Cortalezzi, M.M. Enhancement of the Fouling Resistance of Zwitterion Coated Ceramic Membranes. Membranes 2020, 10, https://doi.org/10.3390/membranes10090210.

18. Susanto, H.; Robbani, M.H.; Istirokhatun, T.; Firmansyah, A.A.; Rhamadhan, R.N. Preparation of lowfouling polyethersulfone ultrafiltration membranes by incorporating high-molecular-weight chitosan with the help of a surfactant. South African Journal of Chemical Engineering 2020, 33, 133-140, https://doi.org/10.1016/j.sajce.2020.07.003.

20. Tan, X.; Rodrigue, D. A review on porous polymeric membrane preparation. Part I: production techniques with polysulfone and poly (vinylidene fluoride). Polymers 2019, 11, https://doi.org/10.3390/polym11071160.

21. Du, X.; Shi, Y.; Jegatheesan, V.; Haq, I.U. A Review on the Mechanism, Impacts and Control Methods of Membrane Fouling in MBR System. Membranes 2020, 10, https://doi.org/10.3390/membranes10020024. 